\title{
Prevalência de Sintomas Depressivos entre Estudantes de Medicina da Universidade Federal de Uberlândia
}

\author{
Prevalence of Depressive Symptoms Among \\ Medicine Students of the University Federal \\ of Uberlândia
}

Carlos Henrique Alves de Rezendel Carolina Borges Abrão ${ }^{I}$

Ediane Palma Coelho ${ }^{I}$

Liliane Barbosa da Silva Passos ${ }^{I}$

\section{PALAVRAS-CHAVE \\ - Depressão; \\ - Estudantes de Medicina; \\ - Epidemiologia; \\ - Educação Médica.}

\section{KEY WORDS}

- Depression;

- Medical Students;

- Epidemiology;

- Medical, Education.

Recebido em: 13/12/2005

Reencaminhado em: 18/07/2007

Aprovado em: 11/10/2007

\section{RESUMO}

Introdução: A formação médica expõe o estudante de Medicina a experiências de estresse, tornando-o potencialmente vulnerável a distúrbios emocionais. Objetivo: Conhecer a prevalência de sintomas depressivos entre os estudantes de Medicina da Universidade Federal de Uberlândia. Método: Os sintomas depressivos foram rastreados por meio do Inventário de Beck (IDB), aplicado a 81\% dos estudantes matriculados no primeiro semestre de 2004. Os pontos de corte para ausência de sintomas depressivos, sintomas leves, moderados e graves foram, respectivamente, 0-3, 4-7, 8-15 e 16 ou mais. Levantaram-se dados demográficos por meio de questionário. Resultados: Dentre os 400 acadêmicos avaliados, houve predominio de jovens, do sexo feminino, solteiros, procedentes de Uberlândia e que moram com os pais. A prevalência de sintomas depressivos foi de $79 \%$, sendo $29 \%$ com grau leve; 31\% moderado e 19,25\% grave. Conclusão: Os resultados indicam uma proporção de sintomas depressivos superior à encontrada na literatura referente a estudantes de Medicina. As excessivas cargas horárias e a ansiedade progressiva com a finalização do curso merecem maior atenção no processo de mudança curricular.

Introduction: Medical graduation exposes students to a series of stressful experiences, which contribute to emotional vulnerability and disturbances. Objective: Obtain information about the prevalence and quality of depressive symptoms among UFU's Medical students. Methodology: Depressive symptoms were traced using Beck's Depression Inventory (BDI), which was applied to $81 \%$ of the Medical students at UFU in the first semester of 2004. Demographic data were collected by means of a questionnaire. The cut points for absence of symptoms, minor, moderated and severe symptoms were 0-3, 4-7, 8-15 and 16 or more points respectively. Results: The predominant characteristics among the 400 evaluated students were young, female, single, native from Uberlândia, and living with their parents. Depressive symptoms occurred in $79 \%$ of the sample. According to BDI scores, $29 \%$ of the students had symptoms of light, $31 \%$ of moderated and $19.25 \%$ of severe depression. Conclusion: The results indicate a rate of depressive symptoms in medicine students higher than that found in the literature. The excessive number of study hours and the increasing anxiety, especially towards the end of the course, should be taken into consideration in the process of curricular changes. 


\section{INTRODUÇÃO}

Nos últimos anos, a saúde mental do universitário tornou-se foco de atenção não só dos especialistas da área de saúde, mas da sociedade em geral. $\mathrm{O}$ estudante universitário está constantemente exposto a situações de estresse, como cobrança dos pais, medo do fracasso e imposições do mercado de trabalho, nas quais a atuação de fatores patogênicos sobre disposições preexistentes, ou não, pode resultar em quadros de neuroses e depressões ${ }^{1}$.

Fazendo a comparação do estresse ocupacional com aquele vivido na universidade, pode-se considerar o estudante como pertencente a um grupo vulnerável, vindo a sofrer reações de ajustamento a situações estressantes provocadas pelo ingresso na vida acadêmica. A reação positiva ou negativa a essas situações se dará mediante dispositivos internos para enfrentar essas questões, que se somam às mudanças ambientais, da própria formação acadêmica².

A categoria médica (tanto acadêmicos como graduados) é extremamente vulnerável a apresentar sintomas depressivos. O contato estreito com portadores de diferentes doenças e prognósticos ruins, a grande carga horária e o volume de matéria a ser estudado, bem como a imposição do alto nível de cobrança, não só pela sociedade ou instituição de ensino, como pelo próprio indivíduo, expõem-no a constantes crises que, muitas vezes, o levam a episódios de depressão ${ }^{3}$.

As faculdades de Medicina são ambientes hostis, de muita competição. Três fases psicológicas enfrentadas por estes acadêmicos devem ser destacadas: (1) euforia inicial, na qual são ativadas crenças de caráter onipotente; (2) decepção, causada pela extrema mudança de hábitos do cotidiano e, às vezes, pelo desempenho insatisfatório nas disciplinas; (3) internato, composto por um período de adaptação e, ao mesmo tempo, por uma alta competitividade pela residência ${ }^{4,5}$.

Além disso, o medo de falhar ou até frustrações quanto à realização profissional e reconhecimento são sentimentos comuns e que, se não forem bem administrados, podem trazer conseqüências ruins à saúde do médico, já que, frente ao erro, este pode ser tomado por sentimento de culpa pelo fracasso e aparente impotência 6 .

Por isso, em termos de saúde mental e devido às preocupações inerentes à profissão, a categoria médica constitui população de risco para vários distúrbios de comportamento, crises e tentativa de suicídio. Esse fato é comprovado pelo número crescente de acadêmicos de Medicina e médicos que optam pela interrupção de suas carreiras, e muitas vezes da própria vida, por causa de transtornos psíquicos ${ }^{7}$.

A depressão entre estudantes de Medicina pode ser uma conseqüência advinda de uma crise - alterações emocionais decorrentes das constantes mudanças ao longo de todo o curso médico. Fatores predisponentes - escolares, pessoais, familiares e socioeconômicos - podem levar a uma situação de crise que, se solucionada de forma dissociativa, ou seja, mal solucionada, pode desencadear sérias doenças, entre elas a depressão ${ }^{8}$.

O conhecimento dos problemas que afligem os estudantes de Medicina é de fundamental importância na execução de planejamento adequado para atender às suas solicitações e também para fornecer subsídios à instituição de ensino, com o intuito de auxiliá-la no aprimoramento da formação discente e de suas relações interpessoais no ambiente universitário9.

Na Universidade Federal de Uberlândia, em especial, muito pouco se estudou sobre o assunto. Visto que estudantes de Medicina estão se preparando para lidar com vidas humanas e suas condições psicológicas podem influenciar em sua formação e futura atuação, é necessário conhecer melhor as condições psíquicas desses acadêmicos.

\section{OBJETIVO GERAL}

Conhecer a prevalência de sintomas depressivos entre estudantes de Medicina da Universidade Federal de Uberlândia (UFU) em 2004.

\section{MÉTODOS}

O estudo de corte transversal realizou-se no primeiro semestre de 2004. Foi convidado a participar do estudo o universo dos estudantes matriculados nesse período, no curso de Medicina da Faculdade de Medicina da Universidade Federal de Uberlândia, após exposição do projeto em sala de aula e mediante a assinatura de termo de consentimento livre e esclarecido. Os participantes foram subdivididos em 12 grupos independentes, correspondentes a cada um dos períodos do curso, para análise estatística.

Os instrumentos utilizados foram um questionário estruturado para informações gerais relativas aos estudantes (Anexo 1) e o Inventário de Beck - $\operatorname{IDB}^{10}$ (Anexo 2).

O IDB é um instrumento de rastreamento de sintomas depressivos, e não um teste diagnóstico, podendo deixar de detectar ou superestimar tais sintomas ${ }^{11}$. É um questionário auto-aplicativo e foi traduzido para vários idiomas e validado em diferentes países, inclusive no Brasil ${ }^{12}$.

Outros estudos semelhantes, como o da Universidade Estadual de Maringá (UEM) ${ }^{3}$, demonstraram a confiabilidade deste inventário.

A escala consiste em 21 itens referentes a tristeza, pessimismo, sensação de fracasso, falta de satisfação, sensação de culpa, sensação de punição, entre outros ${ }^{11}$. A mesma possui quatro categorias de classificação dos sintomas depressivos, subdivididas por escores: 0-3 (nenhum ou mínimo); 4-7 (leve); 8-15 (moderado); 16 ou mais (grave). 
Os sujeitos não foram identificados, exceto pelo orientador, por meio de codificação que permitisse localizar os casos classificados como graves para possível intervenção, o que foi explicado a todos os participantes.

Os instrumentos foram aplicados pelas orientandas, após padronização, em formulários próprios (Anexos 1 e 2) e digitados no banco Access ${ }^{\circledR}$. Foi realizada a estatística descritiva dos resultados e, com o objetivo de verificar a existência ou não de correlações significantes entre as variáveis, foram aplicados o teste do qui-quadrado, o Coeficiente de Contingência $\mathrm{C}^{13}$ e o teste $\mathrm{t}$ de Student ${ }^{14}$.

O projeto foi avaliado e aprovado pelo Comitê de Ética e Pesquisa da Universidade Federal de Uberlândia.

\section{RESULTADOS}

Dentre os 494 acadêmicos matriculados, 400 foram avaliados, 1 se recusou a participar da pesquisa e 93 não foram encontrados no campus no momento da aplicação dos instrumentos. Isso corresponde a uma taxa de participação de $80,97 \%$ do universo dos estudantes matriculados.

Houve maior tendência do sexo feminino (F), de $56 \%$ sobre o masculino $(\mathrm{M})$, correspondendo a uma razão $\mathrm{F} / \mathrm{M}$ de 1,27 . As idades dos sujeitos do sexo masculino variaram de 17 a 30 anos, com média de 22 anos e dois meses e desvio padrão de dois anos e cinco meses, enquanto as do sexo feminino variaram de 16 a 49 anos, com média de 21 anos e oito meses e desvio padrão de três anos e um mês.

Os acadêmicos eram predominantemente solteiros (96\%), sendo casados apenas 3,5\%, desquitados apenas $0,25 \%$ e 1 pessoa não respondeu $(0,25 \%)$. Cerca de $57,25 \%$ moravam no momento com os pais, $19,50 \%$ em pensionato, hotel ou república, $13,25 \%$ com outros familiares, $7 \%$ sozinhos, apenas $2,75 \%$ com o cônjuge e $0,25 \%$ se enquadraram em outras opções.

Quanto ao município de procedência dos acadêmicos, 200 (50\%) eram de Uberlândia, 133 (33,25\%), de outros municípios de Minas Gerais, enquanto 65 (16,25\%) procediam de outro estado e $1(0,25 \%)$ de outro país, além de $1(0,25 \%)$ que não respondeu ao quesito.
A grande maioria não realizava atividade remunerada $(88,25 \%)$, sendo que 27 estudantes $(6,75 \%)$ praticavam atividade acadêmica e 19 (4,75\%), trabalho remunerado, como fonte extra de renda; 1 (0,25\%) não respondeu.

Quanto às atividades de lazer, observou-se que $43,50 \%$ dos acadêmicos sempre as praticavam, 45,0\% raramente, enquanto $11,50 \%$ o faziam raramente.

Do total de estudantes avaliados, $72 \%$ referiram nunca terem feito tratamento psicológico, $24 \%$ já fizeram, sendo que apenas 16 acadêmicos (4\%) estavam em tratamento, dos quais 15 eram do sexo feminino. A maioria dos estudantes não havia feito tratamento psiquiátrico (93,00\%), enquanto $5,25 \%$ já se submeteram à terapêutica, $1,25 \%$ estão com tratamento em andamento e $0,50 \%$, ou seja, 2 acadêmicos, não responderam (Figura 1).

\section{FIGURA 1}

Distribuição dos acadêmicos de Medicina da UFU, segundo a realização de tratamentos psicológicos e psiquiátrico, 2004

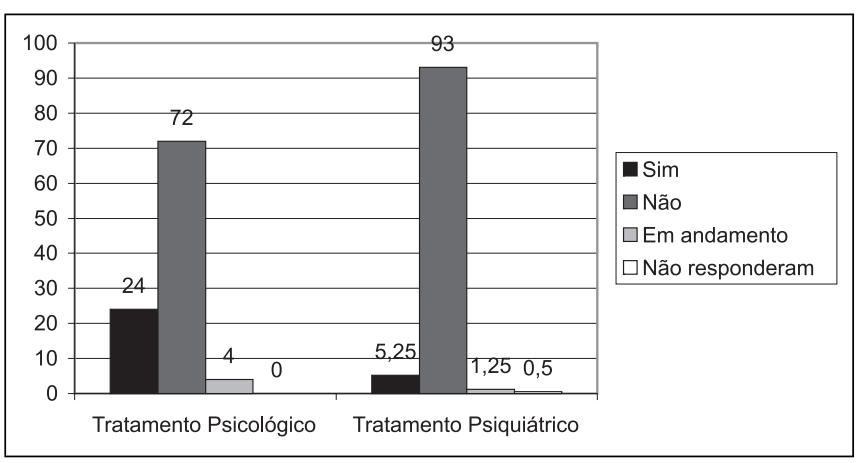

O grau de satisfação com o curso de Medicina foi classificado predominantemente como bom (54,75\%), sendo que $19,50 \%$ julgam o curso excelente, 20,75\% razoável, 4,25\% o consideram ruim, e apenas $0,25 \%$ como péssimo; 2 acadêmicos não responderam (0,50\%).

Em relação à pontuação obtida no IDB, observamos certa homogeneidade quanto aos graus sugestivos de depressão, verificando maior freqüência em torno da classificação leve a moderada (Tabela 1).

\section{TABELA 1}

Distribuição segundo sexo e pontuação obtida no IDB pelos acadêmicos do curso de Medicina da UFU, 2004

\begin{tabular}{|c|c|c|c|c|c|c|}
\hline \multirow{2}{*}{ Pontuação -Classificação } & \multicolumn{2}{|c|}{ Feminino } & \multicolumn{2}{|c|}{ Masculino } & \multicolumn{2}{|c|}{ Total } \\
\hline & $\mathbf{n}$ & $\%$ & $\mathbf{n}$ & $\%$ & $\mathbf{n}$ & $\%$ \\
\hline 0 a 3 -nenhum & 33 & 14,73 & 50 & 28,41 & 83 & 20,75 \\
\hline 4 a 7 -leve & 63 & 28,12 & 53 & 30,11 & 116 & 29,00 \\
\hline 8 a 15 - moderado & 79 & 35,27 & 45 & 25,57 & 124 & 31,00 \\
\hline 16 ou mais - grave & 49 & 21,88 & 28 & 15,91 & 77 & 19,25 \\
\hline Total & 224 & 100,00 & 176 & 100,00 & 400 & 100,00 \\
\hline
\end{tabular}


TABELA 2

Distribuição segundo pontuação obtida no IDB e período cursado pelos acadêmicos do curso de Medicina da UFU, 2004

\begin{tabular}{|c|c|c|c|c|c|c|c|c|c|c|}
\hline \multirow[t]{2}{*}{ Período } & \multicolumn{2}{|c|}{ Nenhum/Mínimo } & \multicolumn{2}{|c|}{ Leve } & \multicolumn{2}{|c|}{ Moderada } & \multicolumn{2}{|c|}{ Grave } & \multicolumn{2}{|c|}{ Total } \\
\hline & $\mathbf{n}$ & $\%$ & $\mathbf{n}$ & $\%$ & $\mathbf{n}$ & $\%$ & $\mathbf{n}$ & $\%$ & $\mathbf{n}$ & $\%$ \\
\hline $1^{\circ}$ & 12 & 32,43 & 14 & 37,84 & 8 & 21,62 & 3 & 8,11 & 37 & 100,00 \\
\hline $2^{\circ}$ & 8 & 20,51 & 12 & 30,77 & 12 & 30,77 & 7 & 17,95 & 39 & 100,00 \\
\hline $3^{\circ}$ & 9 & 23,08 & 15 & 38,46 & 7 & 17,95 & 8 & 20,51 & 39 & 100,00 \\
\hline $4^{\circ}$ & 14 & 35,90 & 13 & 33,33 & 11 & 28,21 & 1 & 2,56 & 39 & 100,00 \\
\hline $5^{\circ}$ & 4 & 10,26 & 9 & 23,08 & 14 & 35,90 & 12 & 30,76 & 39 & 100,00 \\
\hline $6^{\circ}$ & 6 & 19,35 & 6 & 19,35 & 10 & 35,26 & 9 & 29,04 & 31 & 100,00 \\
\hline $7^{\circ}$ & 2 & 6,07 & 9 & 27,27 & 13 & 39,39 & 9 & 27,27 & 33 & 100,00 \\
\hline $8^{\circ}$ & 5 & 14,29 & 10 & 28,57 & 18 & 51,43 & 2 & 5,71 & 35 & 100,00 \\
\hline $9^{\circ}$ & 3 & 9,10 & 8 & 24,24 & 14 & 42,42 & 8 & 24,24 & 33 & 100,00 \\
\hline $10^{\circ}$ & 13 & 43,33 & 6 & 20,00 & 6 & 20,00 & 5 & 16,67 & 30 & 100,00 \\
\hline $11^{\circ}$ & 7 & 21,88 & 9 & 28,12 & 8 & 25,00 & 8 & 25,00 & 32 & 100,00 \\
\hline $12^{\circ}$ & 1 & 6,25 & 6 & 37,50 & 4 & 25,00 & 5 & 31,25 & 16 & 100,00 \\
\hline Total & 84 & 20,84 & 117 & 29,03 & 125 & 31,02 & 77 & 19,11 & 403 & 100,00 \\
\hline
\end{tabular}

Considerando-se os sintomas depressivos em geral, independentemente de seu grau, verificou-se uma freqüência de $79 \%$ entre a população estudada.

Foram demonstradas correlações negativas significantes entre a variável "pontuação obtida no IDB" e as seguintes variáveis: atividade de lazer, tratamento psicológico, tratamento psiquiátrico e grau de satisfação com o curso $(p<0,05)$.

Foi encontrada correlação positiva significante entre as variáveis "pontuação obtida no IDB" e períodos cursados pelos alunos $(\mathrm{p}<0,05)$, indicando que, quanto mais elevado o período, maiores os valores de pontuação no IDB. A mesma correlação não foi observada para a variável idade.

A comparação entre os resultados obtidos por elementos do sexo masculino e do sexo feminino, com relação à pontuação obtida no IDB, foi analisada por meio do teste $t$ de Student $^{14}$, com nível de significância estabelecido em 0,05 , em uma prova bilateral.

O resultado foi $p=0,001$, indicando que houve diferenças significantes entre a pontuação obtida por elementos do sexo feminino e do masculino, sendo que os valores mais elevados foram os obtidos pelos elementos do sexo feminino.

\section{DISCUSSÃO}

Houve predominância de acadêmicos do sexo feminino, o que só vem confirmar que, no Brasil, há um processo de aumento marcante de mulheres na profissão médica. A tendência crescente da participação feminina na Medicina vem de algumas décadas, ocorrendo em diversos países ${ }^{15}$, como conseqüência de mudanças culturais e socioeconômicas ${ }^{16}$. Mesmo com o maior número de participantes do sexo feminino, verificouse diferença significativa de pontuação no IDB, com valores maiores obtidos pelas estudantes. Isso está de acordo com trabalhos da literatura, que demonstraram maior freqüência de sintomas depressivos em mulheres, tanto no meio acadêmico como na população geral ${ }^{9,17-22}$.

O sexo feminino parece não ser um fator de risco por si só, mas, sim, o ambiente e suporte social na maioria das culturas $^{17}$. Investigações recentes apontam que mulheres com filhos pequenos e empregos com jornada integral podem estar sob maior risco de desenvolver transtornos mentais ${ }^{19}$.

$\mathrm{O}$ fato de os homens relatarem menos sintomas depressivos do que as mulheres também colabora para a menor freqüência de depressão encontrada entre eles ${ }^{17}$. Millan, Rossi e De Marco (1995) ${ }^{9}$ realizaram estudo a respeito da procura espontânea de assistência psicológica pelo estudante de Medicina e verificaram que o número de acadêmicas que procuraram assistência foi duas vezes superior ao de acadêmicos. Deram como explicações possíveis o fato de as mulheres apresentarem maior grau de psicopatologia, serem menos resistentes do que os homens na procura de ajuda psicológica e apresentarem maior disponibilidade interna para o autoconhecimento.

Quanto à idade dos acadêmicos, verificou-se maior freqüência de indivíduos jovens, com média de 21 anos e 11 meses, não sendo demonstrada correlação significante entre a idade e a pontuação obtida no IDB. Segundo dados da literatura, a idade de começo dos transtornos depressivos situa-se entre 20 e 40 anos, sendo que fatores sociais podem colocar as pessoas mais jovens em maior risco ${ }^{17}$.

Os jovens universitários em geral são mais susceptíveis a alterações emocionais pela própria situação social a que estão sujeitos, já que se sentem maduros biologicamente para serem socialmente adultos, mas, na verdade, têm status de adoles- 
cente, pois vivenciam um longo ritual de iniciação antes de serem liberados para os papéis a que estão destinados ${ }^{1,8}$.

O presente estudo não mostrou resultados significativos da relação entre condição atual de moradia e procedência com as pontuações do IDB. No entanto, do ponto de vista epidemiológico, há associação entre família e aspectos depressivos. Isto porque o ambiente familiar é um dos fatores protetores, importantes no risco de depressão. Identificadas em estudos de adolescentes expostos ao estresse, particularmente, a relação parental e a qualidade do vínculo têm demonstrado redução dos efeitos deletérios do estresse, promovendo uma adaptação funcional. Em estudo com estudantes de Medicina colombianos, Gaviria, Rodriguez e Alvarez (2002) demonstraram um aumento do risco de depressão à medida que diminuía a qualidade da relação familiar ${ }^{18}$. Estas condições são mais pertinentes à situação universitária, que, desligada de seu meio familiar, está mais exposta às complicações sentimentais. Especialmente porque jovens selecionados por meio dos atuais exames vestibulares, provenientes de variados recantos do país, por vezes do exterior, geralmente em condições financeiras desfavoráveis, de diferentes culturas, convicções religiosas, tendências ideológicas e filosóficas, são reunidos de forma arbitrária em alojamentos. Criam-se condições ideais para a contaminação recíproca de hábitos, costumes e práticas, resultando em atitudes coletivas de protesto e até em desvios na esfera sexual ou consumo de tóxicos. A carência se torna mais intensa nesses lugares ${ }^{1}$. Além disso, a depressão é um transtorno psiquiátrico de alta prevalência e com um curso crônico e recidivante em que os fatores estressantes, como a disfunção familiar, podem contribuir para sua manifestação, que, no caso dos estudantes de Medicina, se somaria ao estresse acadêmico ${ }^{18}$

Segundo um estudo no qual 100 estudantes de Medicina foram entrevistados, os fatores predisponentes de crise são, por ordem de freqüência: escolares, pessoais, familiares e socioeconômicos. Estes estudantes consideram que resolveram suas crises com os seguintes "agentes terapêuticos", por ordem de freqüência: apoio da família, encontro amoroso, melhora das relações familiares, melhoria das condições econômicas, atividades esportivas, religião, psicoterapia e trancamento da matrícula ${ }^{8}$.

Observa-se que um dos problemas mais freqüentes que levam ao suicídio no meio médico são os problemas familiares atuais?.

Não foi possível observar correlação significante entre a variável estado civil e pontuação no IDB. Contudo, o casamento, mais freqüentemente, agrava a situação, pelas responsabilidades acarretadas, a menos que, em caráter excepcional, o cônjuge que já trabalha possa fazer face às dificuldades materiais existentes ${ }^{1}$.

Segundo Silva $(2002)^{20}$, situações estressantes, como dificuldades conjugais, estão associadas a um aumento substancial do risco de início de um transtorno depressivo maior. $\mathrm{O}$ fator mais associado com o começo da depressão na vida adulta é a perda do cônjuge.

Os resultados do presente estudo não demonstraram correlações significantes entre a variável "pontuação obtida no IBD" e o exercício de atividade remunerada pelo estudante, sendo que os acadêmicos predominantemente não praticam atividade remunerada alguma.

Uma investigação realizada pelo Instituto de Pesquisas Econômicas (IPE) da USP revelou, de forma surpreendente, que um elevado número de estudantes de Medicina (quase $30 \%$ ) trabalha, e, sendo alunos de terceiro ano, não se trata de estágios ou internato, mas de serviços raramente relacionados à sua futura profissão. O estudante, então, suporta uma excessiva sobrecarga que em longo prazo pode representar um comprometimento tanto emocional como, não excepcionalmente, somático ${ }^{1}$.

Já outros estudos mostram que é freqüente aparecer nessa fase uma questão de ordem financeira, visto que o estudante de Medicina, com raras exceções, não tem condições de ter renda própria, advinda de sua atividade profissional, e, portanto, depende mais dos pais. A conclusão a que chegam é pouco favorável à sua auto-imagem, começando a ver a si mesmos como inúteis, que não trabalham e que nada realizam na vida ${ }^{5}$

Os resultados obtidos nesse estudo inerentes à relação entre a prática de atividades de lazer pelos estudantes e as pontuações obtidas pelo IBD demonstraram uma correlação negativa estatisticamente significativa entre as variáveis citadas, que se mostraram, portanto, inversamente proporcionais.

Essa mesma correlação pode ser observada em um estudo realizado com universitários do primeiro ano da Southern Illinois University School of Medicine. Nele se concluiu que os alunos com elevados escores de estresse e ansiedade eram aqueles que exerciam nenhuma ou pouca atividade de lazer. Os autores enfatizam, portanto, a necessidade de esclarecer os estudantes quanto aos benefícios do bom aproveitamento dos períodos de lazer como um mecanismo de escape das pressões e ansiedades vividas no dia-a-dia ${ }^{23}$.

Foi encontrada correlação negativa e estatisticamente significativa entre as variáveis de tratamento psicológico e psiquiátrico e a pontuação obtida com o IDB. Na literatura investigada, não foram encontrados trabalhos que discutissem tal correlação. Entretanto, no presente estudo, mesmo que a 
motivação dos tratamentos tenha sido inclusive depressão, há que se supor que tais cuidados amenizem as manifestações depressivas, detectáveis num corte seccional, como no caso.

A correlação entre o grau de satisfação dos estudantes de Medicina com o seu curso e a pontuação obtida com o IBD mostrou-se negativa e significativa sob o ponto de vista estatístico. Esses resultados traduzem a realidade de que, quanto maior a satisfação do estudante com o seu curso, maior é o seu grau de envolvimento e engajamento com o mesmo, reduzindo, portanto, a presença de sintomas depressivos, o que se traduz em menor pontuação no IBD. Tal correlação foi evidenciada em estudo realizado por Clark e Zeldow (1988) ${ }^{24}$, no qual foi observado que os acadêmicos que apresentaram as menores notas durante o primeiro ano do curso eram os mesmos que obtiveram pontuação no IBD acima de 21, ou seja, que apresentavam sintomas depressivos graves.

Os autores citam, ainda, que a insatisfação dos acadêmicos com o currículo tradicional das escolas médicas vem aumentando drasticamente e recomendam que as futuras avaliações dos currículos incluam uma nova visão do processo de educação médica e seu impacto na saúde e bem-estar dos estudantes ${ }^{24}$. Essa relação é encontrada não somente no caso dos estudantes de Medicina, mas da população em geral. Quando o indivíduo tem alto grau de satisfação com seu trabalho ou atividade acadêmica, os riscos de aparecimento de sintomas depressivos, que muitas vezes simplesmente traduzem sentimentos de insatisfação, são bem menores.

Quanto à prevalência de sintomas depressivos, encontrada no presente estudo, observa-se que é superior aos dados da literatura, o que alerta para a necessidade da adoção de medidas. Segundo Fleck et al. $(2003)^{25}$, a prevalência de depressão em populações específicas está em torno de 30\% a 50\%. O mesmo foi observado por Santos et al. $(2003)^{21}$, que realizaram estudo com estudantes de Enfermagem utilizando também o IDB e verificaram uma freqüência de $41 \%$ de acadêmicos com diferentes graus de depressão.

Para amostras de pacientes com transtorno afetivo, o Center for Cognitive Therapy recomenda os seguintes pontos de corte para o IDB: menor que $10=$ sem depressão ou depressão mínima; de 10 a 18 = depressão, de leve a moderada; de 19 a 29 = depressão, de moderada a grave; de 30 a 63 = depressão grave. Já para amostras não diagnosticadas, as diretrizes são diferentes ${ }^{11}$. Como no presente estudo foi utilizado um ponto de corte menor, mais rigoroso, portanto, pode-se justificar a maior prevalência encontrada. Contudo, o estudo realizado entre os estudantes de Medicina da Universidade Estadual de Maringá, baseado no IDB com os mesmos valores utilizados aqui, detectou prevalência de depressão de $49,2 \%{ }^{3}$, que ainda é inferior à verificada nos estudantes de Uberlândia.

Em relação aos períodos cursados pelos acadêmicos, foi verificado que, à medida que o estudante avança no curso, a tendência é que apresente mais sintomas depressivos, já que encontramos correlação significante entre a pontuação obtida no IDB e o período cursado pelos alunos. Isso pode ser explicado pela própria trajetória do estudante, que passa pela euforia inicial, defrontando-se com as mudanças no estilo de vida, por decepções quanto a suas expectativas em relação ao curso $^{4}$ e, principalmente, pela transição entre a ciência básica e as práticas clínicas ${ }^{3,18}$.

Posteriormente, segue-se um período de melhora pela adaptação ao treinamento clínico ${ }^{3,21}$, até que surge novamente uma fase de angústia, motivada pela expectativa de se formar e entrar no mercado de trabalho, fazer prova de residência, bem como pela dúvida na escolha da especialidade ${ }^{4}$.

Segundo Guimarães et al. $(2000)^{26}$, dificuldade de organização do estudo, competitividade, distanciamento dos professores, intensa quantidade de informações, limite das atividades de lazer, frustrações com o ciclo básico, contato com o sofrimento e a morte, contato com a realidade dos serviços de saúde, processo de escolha da especialidade, exame de residência médica, perspectivas do mercado de trabalho e a sensação de não saber nada são fatores desencadeantes do aumento progressivo do grau de estresse entre os alunos no decorrer do curso.

\section{CONCLUSÃO}

Os resultados indicam uma proporção de sintomas depressivos superior à encontrada na literatura geral e específica em relação a estudantes de Medicina, com predomínio de escores mais elevados no sexo feminino. Os tratamentos psicológicos e psiquiátricos, quando relatados, decorreram em escores mais baixos, apontando a necessidade de apoio institucional e ampliação de acesso aos programas existentes. As excessivas cargas horárias e a ansiedade progressiva com a finalização do curso merecem maior atenção no processo de mudança curricular.

\section{REFERÊNCIAS}

1. Fortes JRA. Saúde mental do universitário. Neurobiologia. 1973; 36 (suplemento): 13-24.

2. Colares MFA. As fontes de tensão no curso médico: um estudo psicométrico. [Dissertação] Ribeirão Preto, Escola de Enfermagem de Ribeirão Preto, Universidade de São Paulo, 1999. 
3. Porcu M, Fritzen VC, Helber C. Sintomas depressivos nos estudantes de Medicina da Universidade Estadual de Maringá. Psiquiatria na Prática Médica. 2001; 34. Disponível em <http://www.unifesp.br/dpsiq/polbr/ppur/original501.htm>. Acesso em 17 de setembro de 2005.

4. Cataldo Neto A, et al. O estudante de medicina e o estresse acadêmico. R.Med.PUCRS. 1998; 8(1): 06-12.

5. Millan LR, et al. Alguns aspectos psicológicos ligados à formação médica. Revista Abp-Apal. 1991; 13(4): 137-142.

6. Meleiro AMAS. Suicídio entre médicos e estudantes de Medicina. Revista da Associação Médica Brasileira. 1998; 44(2): 135-140.

7. D`Andrea FF, Achatz MH. Sentimentos e opiniões de médicos residentes e estudantes de medicina sobre suicídio em seu meio. Jornal Brasileiro de Psiquiatria. 1987; 36(6): 329-333.

8. D`Andrea FF, Almeida OML. Crise em estudantes de Medicina. Jornal Brasileiro de Psiquiatria. 1988;37(6): 313-315.

9. Millan LR, Rossi E, De Marco OLN. A procura espontânea de assistência psicológica pelo estudante de Medicina. Revista Abp-Apal. 1995; 17(1): 11-16.

10. Beck AT, et al. An Inventory for Measuring Depression. Archivves of General Psychiatry. 1961; 4: 53-63.

11. Sandri A et al. Interconsulta psiquiátrica no hospital geral: diagnóstico da situação total. Revista de Psiquiatria. 2000; 22: 138-147.

12. Gorestein C, Andrade L. Inventário de depressão de Beck: propriedades psicométricas da versão em português. Rev Psiq Clin 1998; 25(5): 245-250.

13. Siegel S. Estatística não-paramétrica para as ciências do comportamento. São Paulo: Mcgraw-Hill, 1975.

14. Graner EA. Estatística. São Paulo: Melhoramentos, 1966.

15. Ferreira RA, et al. O estudante de medicina da Universidade Federal de Minas Gerais: perfil e tendências. Revista da Associação Médica Brasileira. 2000; 46(3): 224-231.

16. Millan LR, et al. What is behind a student's choice for becoming a doctor? Clinics. 2005; 60(2): 143-150.

17. Lima MS. Epidemiologia e impacto social. Revista Brasileira de Psiquiatria. 1999;21(supl.1): 01-05.

18. Gaviria S, Rodriguez MA, Alvarez T. Calidad de la relación familiar y depresión en estudiantes de Medicina de Medellín, Colombia, 2000. Rev. Chil. Neuro-Psiquiatr. Santiago. 2002; 40(1): 41-46.

19. Menezes PR, Nascimento AF. Epidemiologia da depressão nas diversas fases da vida. In: Lafer B. et al. Depressão no coclo de vida. Porto Alegre: Artes Médicas, 2000. P 31-36.

20. Silva H. Nuevas perspectivas em la biologia de la depresión. Rev.Chil. Neuro-Psiquiatr. 2002; 40(Suppl.1): 9-20.
21. Santos TM, et al. Aplicação de um instrumento de avaliação do grau de depressão em universitários do interior paulista durante a graduação em Enfermagem. Acta Sciences. 2003; 25(2): 171-176.

22. Moro A, Valle JB, Lima LP. Sintomas depressivos nos estudantes de Medicina da Universidade da Região de Joinville (SC). Revista Brasileira de Educação Médica. 2005; 29(2): 97-102.

23. Folse ML, Da Rosa DA, Folse R. The relationship between stress and attitudes toward leisure among first-year medical students. J. Med. Educ. 1985; 60(8): 610-617.

24. Clark DC, Zeldow PB. Vicissitudes of Depressed Mood During Four Years of Medical School. JAMA,1988; 260(17): 2521-2527.

25. Fleck MPA, et al. Diretrizes da Associação Médica Brasileira para o tratamento da depressão (versão integral). Revista Brasileira de Psiquiatria. 2003; 25(2): 114-122.

26. Guimarães RGM e cols. O que mudou em nossas vidas? Os alunos de Medicina na vivência do curso médico. Anais do $38^{\circ}$ Congresso Brasileiro de Educação médica Petrópolis (RJ): ABEM, 2000; p. 113-14.

\section{CONFLITOS DE INTERESSE}

Declarou não Haver

\section{ENDEREÇO PARA CORRESPONDÊNCIA}

Carlos Henrique Alves de Rezende

Rua Dr. Luiz Antonio Waack, 1080 - Umuarama

38402-030 - Uberlândia - MG

E-mail: charezende@ufu.br

\section{ANEXO 1}

$\begin{array}{ll}\text { Data: _L_____anos } & \\ \text { Sexo: ( ) F ( ) M } & \\ \text { Período: } & \\ \text { Local de procedência: } & \text { ( ) Uberlândia } \\ & \text { ( ) Outros municípios de MG } \\ & \text { ( ) Outros estados } \\ & \text { ( ) Outro país } \\ \text { Estado civil: } & \text { ( ) solteiro } \\ & \text { ( ) casado } \\ & \text { ( ) desquitado/divorciado } \\ & \text { ( ) amasiado } \\ & \text { ( ) viúvo }\end{array}$


Situação atual de moradia:
( ) sozinho
( ) com os pais
( ) com outros familiares
( ) com o cônjuge
( ) pensionato / hotel / república
( ) outros

Atividade remunerada:
( ) nenhuma
( ) trabalho remunerado
( ) atividade acadêmica (PET, bolsa de estágio, pesquisa, monitoria, etc.)

Já fez tratamento psicológico?

( ) $\operatorname{sim}$ ( ) não ( ) em andamento

Já fez tratamento psiquiátrico?

$$
\text { ( ) } \operatorname{sim} \text { ( ) não ( ) em andamento }
$$

Faz atividades de lazer, como esportes, música, dança, cinema, entre outros?

$$
\begin{aligned}
& \text { ( ) sempre } \\
& \text { ( ) esporadicamente } \\
& \text { ( ) raramente }
\end{aligned}
$$

Como você classificaria o seu grau de satisfação com o curso escolhido (atual)?

$$
\begin{aligned}
& \text { ( ) péssimo } \\
& \text { ( ) ruim } \\
& \text { ( ) razoável } \\
& \text { ( ) bom } \\
& \text { ( ) excelente }
\end{aligned}
$$

\section{ANEXO 2}

Este questionário consiste em 21 grupos de afirmações. Depois de ler cuidadosamente cada grupo, faça um círculo em torno do número $(0,1,2$ ou 3$)$ diante da afirmação, em cada grupo, que descreve melhor a maneira como você tem se sentido nesta semana, incluindo hoje. Se várias afirmações num grupo parecerem se aplicar igualmente bem, faça um círculo em cada uma. Tome o cuidado de ler todas as afirmações, em cada grupo, antes de fazer a sua escolha.

1. 0 Não me sinto triste.

1 Eu me sinto triste.

2 Estou sempre triste e não consigo sair disso.

3 Estou tão triste ou infeliz que não consigo suportar.

2. 0 Não estou especialmente desanimado quanto ao futuro.

1 Eu me sinto desanimado quanto ao futuro.

2 Acho que nada tenho a esperar.

3 Acho o futuro sem esperança e tenho a impressão de que as coisas não podem melhorar.
3. 0 Não me sinto um fracasso.

1 Acho que fracassei mais do que uma pessoa comum.

2 Quando olho para trás, na minha vida, tudo o que posso ver é um monte de fracassos.

3 Acho que, como pessoa, sou um completo fracasso.

4. 0 Tenho tanto prazer em tudo como antes.

1 Não sinto mais prazer nas coisas como antes.

2 Não encontro um prazer real em mais nada.

3 Estou insatisfeito ou aborrecido com tudo.

5. 0 Não me sinto especialmente culpado.

1 Eu me sinto culpado às vezes.

2 Eu me sinto culpado na maior parte do tempo.

3 Eu me sinto sempre culpado.

6. 0 Não acho que esteja sendo punido.

1 Acho que posso ser punido.

2 Creio que vou ser punido.

3 Acho que estou sendo punido.

7. 0 Não me sinto decepcionado comigo mesmo.

1 Estou decepcionado comigo mesmo.

2 Estou enojado de mim.

3 Eu me odeio.

8. 0 Não me sinto de qualquer modo pior que os outros.

1 Sou crítico em relação a mim devido a minhas fraquezas ou meus erros.

2 Eu me culpo sempre por minhas falhas.

3 Eu me culpo por tudo de mal que acontece.

9. 0 Não tenho quaisquer idéias de me matar.

1 Tenho idéias de me matar, mas não as executaria.

2 Gostaria de me matar.

3 Eu me mataria se tivesse oportunidade.

10. 0 Não choro mais que o habitual.

1 Choro mais agora do que costumava.

2 Agora, choro o tempo todo.

3 Costumava ser capaz de chorar, mas agora não consigo mesmo que o queira.

11. 0 Não sou mais irritado agora do que já fui.

1 Fico molestado ou irritado mais facilmente do que costumava.

2 Atualmente me sinto irritado o tempo todo.

3 Absolutamente não me irrito com as coisas que costumavam irritar-me. 
12. 0 Não perdi o interesse nas outras pessoas.

1 Interesso-me menos do que costumava pelas outras pessoas.

2 Perdi a maior parte do meu interesse nas outras pessoas.

3 Perdi todo o meu interesse nas outras pessoas.

13. 0 Tomo decisões mais ou menos tão bem como em outra época.

1 Adio minhas decisões mais do que costumava.

2 Tenho maior dificuldade em tomar decisões do que antes.

3 Não consigo mais tomar decisões.

14. 0 Não sinto que minha aparência seja pior do que costumava ser.

1 Preocupo-me por estar parecendo velho ou sem atrativos. 2 Sinto que há mudanças permanentes em minha aparência que me fazem parecer sem atrativos.

3 Considero-me feio.

15. 0 Posso trabalhar mais ou menos tão bem quanto antes.

1 Preciso de um esforço extra para começar qualquer coisa.

2 Tenho de me esforçar muito até fazer qualquer coisa.

3 Não consigo fazer nenhum trabalho.

16. 0 Durmo tão bem quanto de hábito.

1 Não durmo tão bem quanto costumava.

2 Acordo uma ou duas horas mais cedo do que de hábito e tenho dificuldade para voltar a dormir.

3 Acordo várias horas mais cedo do que costumava e tenho dificuldade para voltar a dormir.
17. 0 Não fico mais cansado que de hábito.

1 Fico cansado com mais facilidade do que costumava.

2 Sinto-me cansado ao fazer quase qualquer coisa.

3 Estou cansado demais para fazer qualquer coisa.

18. 0 Meu apetite não está pior do que de hábito.

$1 \mathrm{Meu}$ apetite não é tão bom quanto costumava ser.

2 Meu apetite está muito pior agora.

3 Não tenho mais nenhum apetite.

19. 0 Não perdi muito peso, se é que perdi algum ultimamente.

1 Perdi mais de $2,5 \mathrm{~kg}$.

2 Perdi mais de $5,0 \mathrm{~kg}$.

3 Perdi mais de $7,5 \mathrm{~kg}$.

Estou deliberadamente tentando perder peso, comendo menos: SIM ( ) NÃO ( )

20. 0 Não me preocupo mais que o de hábito com minha saúde.

1 Preocupo-me com problemas físicos, como dores e aflições ou perturbações no estômago ou prisão de ventre.

2 Estou muito preocupado com problemas físicos e é difícil pensar em outra coisa que não isso.

3 Estou tão preocupado com meus problemas físicos que não consigo pensar em outra coisa.

21. 0 Não tenho observado qualquer mudança recente em meu interesse sexual.

1 Estou menos interessado por sexo do que costumava.

2 Estou bem menos interessado em sexo atualmente.

3 Perdi completamente o interesse por sexo. 